\title{
Problems of Application of Digital Technologies in International Trade
}

\author{
Tatyana Vorotyntseva \\ Peoples' Friendship University of Russia RUDN \\ Moscow, Russia \\ mstata67@ list.ru
}

\author{
Gulzida Nemirova \\ Russian customs academy \\ Lyubertsy, Russia \\ g.nemirova@ customs-academy.ru
}

\author{
Artyom Vinichenko \\ Russian customs academy \\ Lyubertsy, Russia \\ ar-vin@mail.ru
}

\begin{abstract}
The experience of blockchain application in international trade on the example of Singapore and South Korea that use this mechanism to improve the efficiency of customs transactions and customs control was studied in the work. The use of this technology undoubtedly gives positive results, which allows us to draw a conclusion about the need for the introduction of digital customs in the member States of the Eurasian economic Union (hereinafter the EAEU). At the same time, the authors highlight the problems that the EAEU member States may face when introducing such technology. At the moment, the legislative framework of the EAEU does not allow the use of electronic documents on a par with paper, electronic documents are not legally significant. To solve the problem, it is necessary to create standards of electronic documents in each industry, including the customs sphere at the level of the EAEU.
\end{abstract}

Keywords: digitalization of industries, blockchain, classification, optimization of trade processes, simplification of interaction, electronic documents, electronic contract form

\section{INTRODUCTION}

The role of advanced technologies used in international trade has increased significantly over the past few years. In the conditions of aspiration of the countries to creation of digital economy it is expedient to analyze potential of innovative technologies for their adaptation to various branches of managing. The most effective technology is the blockchain (a chain of connected blocks). The concept of blockchain technology was developed in 2008, but has been developed only in the last five years, as a tool to improve information security and digitalization of various industries. For effective use of technology it is necessary to consider the conceptual apparatus characterizing the classification of this technology.

\section{MEthods}

The theoretical basis of the research is the results of the development of domestic and foreign scientists in the field of digital technologies. The methodological basis is the theory and methodology of a systematic approach to the analysis of the use of blockchain technologies in customs regulation and customs control.

By their nature, technological revolutions are very destructive. In the early 19th century, there were attempts to destroy machines, despite the fact that machines opened up the opportunity to increase productivity and increase jobs. This violation occurs precisely because the new technology is not adapted [1]. The same pattern we observed in the introduction of blockchain technology.

William Magyar describes the blockchain as a technology that continuously records all transactions. This technology allows you to save all the information, not allowing you to erase certain operations or data. Blockchain is a kind of database through which it is possible to trace the entire history of operations [2].

Blockchain is a decentralized system in contrast to the banking system, which is headed by a Central Bank. The decentralized system avoids the involvement of intermediaries in the process, reducing it to a simple «sender-receiver» interaction. It is necessary to note the importance of the differences between the classical database and the blockchain. These differences lie in the fact that in any database there is an intermediary who can delete an operation from the database, and in the blockchain, each operation is confirmed by a distributed registry confirming the execution of the operation, which can not be deleted from memory. Thus, the blockchain 
in business makes it possible to reduce the costs of intermediaries in the Commission of foreign trade operations.

There is a classification of types of blockchain, in which the main criterion is the degree of openness of the platform for participants. Below are the following types of technologies considered on the basis of openness.

1) The Public blockchain. In this form of blockchain, any information ceases to be confidential. It is an open chain of blocks that any participant can join and upload any information. This species is fully decentralized and distributed. There is no possibility to change any data in the public blockchain. An example of such a system is Ethereum.

2) Blockchain consortium. It is used if access to information should be provided for several users at the same time. Access to the chain can be public, private and mixed. At the mixed type the part of information is public, but at the same time there is a problem of limitation of quantity of requests, transactions. Such a system is called partially decentralized.

3) Private blockchain. Suitable for private companies, one organization whose data should be available only to its employees. Each member of the platform must obtain permission to record, verify data, etc. Participants are given different levels of access to information. Unlike public blockchains, private blockchains are a fully centralized system that allows you to control the confidentiality of data.

On the same basis of openness, but with other species differences, the classification is presented by the chief scientific adviser of the UK - Mark Walport:

1) Open public registers. These include registries in which there are no restrictions on access to block data. Any participant can access and make a transaction without restrictions.

2) Closed public registers. Information is provided to members of multiple companies that are granted access.

3) Closed private registries. Access to data is granted only to certain participants, usually employees of an organization.

Closed blockchains, unlike open ones, have the advantage of protection against interference, that is, developers can not affect the data, change it, delete it. Such blockchains allow to ensure data security, it becomes almost impossible to attack the system.

Private blockchains have their advantages, for example, transactions in a company using such a chain of blocks become much cheaper, the speed of transaction confirmation increases and the ability to cancel a certain transaction.

In the context of the digital economy, the role of blockchain as a secure technology is strategically increasing. If you are using the blockchain in customs information technologies, there is a need for the introduction of the term «customs security» [3]. In fact, the blockchain provides the opportunity to directly transfer property rights to another person without the involvement of external guarantors via the Internet, the technology itself guarantees its safety and reliability, there is no Commission for transactions, all transactions are carried out free of charge. This system will be able to verify the transaction electronically. Digital transformation takes place primarily in business, but it also has an impact on organizations such as government agencies, government agencies and organizations that are involved in solving social problems such as pollution or aging populations through the use of existing and new technologies. It has a comprehensive impact on the activities of the customs authorities of Russia, including the process of providing public services [4].

Not only Russian customs authorities use digital technologies in their activities. Scientists assessing the use of digital customs in Europe, note the increase in the effectiveness of the customs control system, the increase in international trade, the opportunity to diversify our international supply chain and reducing the time of release of goods under customs procedures [5]. At the same time, in the conceptual context, there are no answers to the question of digital customs as a system, and what elements form it. Thus, the formation of approaches to the creation of the conceptual apparatus of digital customs within the framework of the functioning of various working bodies of the World customs organization [6].

\section{RESUlTS}

The blockchain platform can provide an opportunity to use smart documents, including standards, regulations, contracts. It should be noted that blockchain can be a profitable solution to increase the efficiency of public services, the use of this platform will reduce the time and financial costs, including simplifying the process of Declaration, certification and licensing up to the complete rejection of the traditional paper form of obtaining these documents. Digital technologies eliminate the need to use or exchange paper documents, and can also play a crucial role in verifying certificates of origin, licenses and other documents. Digital technologies are currently used by customs and trade organizations of different countries.

Singapore is a country with advanced technology in the field of customs. Singapore has now established a national trading platform (NTP), which acts as a single trading information management platform to support companies engaged in foreign trade, logistics and Finance.

The platform is based on the use of blockchain and is aimed at ensuring the supply chain and financing. NTP provides end-to-end digital Commerce. Traders can use a range of trade-related digital services, such as customs Declaration and customs payment control, which will allow them to easily organize shipments, improve cash flows and better manage trade compliance.

NTP also provides an opportunity to improve operational efficiency, for example, by sharing key digital documents such as invoices and permits [7].

The platform helps to ensure the transition to fully paperless trade, which will reduce costs, both from the state and from business in domestic trade and internationally. 
KCS and Samsung SDS are developing a blockchain-based customs platform for issuing certificates of origin, an important international trade document that certifies that goods in a particular export shipment are fully manufactured or processed in a particular country.

Thus, it can be concluded that blockchain is a modern efficient platform. Traditionally, the flow of information is handled by manual processes, and the supply chain slows down when there are many points of communication within it. The use of blockchain technology for direct exchange of documents and information through a decentralized network to increase transparency, eliminate counterfeits, disputes and unnecessary risks will be a key factor to improve the efficiency of trade. Many scientists call this system the technology of the future. According to the forecasts of the world economic forum, already $10 \%$ of world GDP will be focused on blockchain in 2027.

\section{DISCUSSION}

During the analysis of the experience of blockchain application in the customs sphere on the example of Singapore and South Korea, it was revealed that this platform has a number of advantages. In the EAEU countries, the transition to the digital economy is one of the priorities. In the context of digitalization, the role of new technologies increases significantly. At the same time, it is worth mentioning the problems that the EAEU member States may face when introducing such technology at the level EAEU. These problems are similar to those identified in the WTO:

- The difference between socio-economic statuses between countries.

- The business environment and internal rules seem to dictate the level of trading opportunities to access the market.

- Problems with the new infrastructure that provides high copying capabilities [11].

In recent years, the state of development of information systems and technologies in customs control in Russia is characterized by a number of features, trends and problems that need to be taken into account to determine the prospects for their use in the customs control system [12]. The priority task of customs authorities is the transition to electronic document management and provision of services in electronic form. However, at the moment, the legislative framework does not allow the use of electronic documents on a par with paper. The main problem is that it is impossible to replace paper documents with electronic ones without changing legislative acts.

At the moment, electronic documents are not legally significant. Automation of paper documents may not give the desired effect, because at the moment the legislation does not stipulate that electronic documents are authentic and can be used on a par with paper.

Electronic documents should be made legally significant not only in the field of customs, but also in other areas. To do this, it is necessary to create standards for electronic 
1) legal force of electronic messages at the conclusion of documents in each industry. The global problem is that these standards should be adopted not by one country, but by all EAEU member States.

Analysis of the level of development of e-Commerce showed that:

1) in all EAEU member States there is a requirement to conclude a contract in writing;

2) there are no legal acts establishing the format of providing electronic documents;

3) Bank guarantee in electronic form can be considered only in the Russian Federation and the Republic of Belarus;

4) the issue of interaction with the use of information systems of state bodies within each state has not been resolved.

Blockchain as a technology is at an early stage of development. There are examples of successful use of blockchain abroad, but in the EAEU countries, only dozens of companies use blockchain. Standardization of processes and systems can take several years. In addition, at the Union level, it is necessary to ensure a one-time transition to the use of this platform.

The customs service of the Russian Federation is a comprehensive institution that fully controls the supply chain of goods [13]. At this stage, customs authorities face many problems, for example, violation of legislation, weak development of the customs control system after the release of goods, the problem of interaction of customs authorities of different member States of the EAEU.

Thus, it can be concluded that before moving to the use of blockchain technology, it is necessary to solve a number of issues at the legislative level such as:

1) creation of a law giving legal force to electronic documents;

2) creating a single document format;

3) improvement of the model of interaction of state bodies;

4) development of uniform standards of electronic documents.

The development of digital technologies can lead to the reduction of barriers, as well as transaction costs, stimulating the growth of output and increasing the indicators of foreign trade (exports or imports), and in addition, strengthening the processes of specialization of countries[14]. Blockchain technology can be a solution to problems such as unnecessary costs, low productivity and efficiency, risk, etc. However, there are a number of problems associated with the introduction of this technology in the EAEU.

The problem of the lack of legislative acts that enshrine the legal significance of electronic documents can be solved by adapting the national legislation of the EAEU member States to the principles of the UNCITRAL model law «On electronic Commerce».

The provisions should address the following items: the transaction;

2) use of electronic documents as evidence in court;

3) criteria of authenticity of electronic documents;

4) conclusion of contracts in electronic form;

5) the legal status of electronic documents as proof of payment.

The problems of implementing blockchain technology at the Union level mainly lie in the difference in legislation. The introduction of technology before the legislation changes will not help to solve the existing problems, but on the contrary will aggravate the situation.

The requirements for the form of an electronic contract are not established in the legislation of the EAEU member States. The UN Convention on contracts provides freedom of choice of form and means of proof in international trade contracts. It will be expedient to introduce a single template and the presentation of minimum requirements for details.

It should be noted that after the entry of the Russian Federation into the world trade organization, special attention is paid to the removal of barriers to international trade [15]. Undoubtedly, the removal of barriers will be facilitated by the use of blockchain technologies in customs control. In the future, it is possible to use smart contracts based on blockchain. The technology of «smart contracts» is aimed at ensuring the fulfillment of all obligations. If a party to the contract in any way violates the terms, he will be forced to pay fines. This technology makes the violation of the contract is very expensive At the same time, smart contracts are code, not artificial intelligence. This technology will allow to get rid of the conclusion of contracts in paper form.

In the digital age, blockchain is truly the technology of the future. However, a wide range of work needs to be done at both the national and Union levels before this technology can be implemented.

\section{REFERENCES}

[1] M. Mühleisen, "The long and short of the digital revolution", Finance and Development, 2018, vol. 55, no. 2 [Electronic resource]. Available at: https://www.imf.org/external/pubs/ft/fandd/2018/06/ impact-of-digital-technology-on-economic-growth/muhleisen.htm.

[2] W. Montgaillard, "Blockchain for business-Moscow", 2018, pp. 12-48 [Electronic resource].

[3] G. Nemirova and S. Novikov, "Organizational and economic mechanism for customs control after the release of goods administration in the economic security system", Proceedings of the 33rd International Business Information Management Association Conference, IBIMA 2019, Education Excellence and Innovation Management through Vision 2020, 2019, pp. 4149-4160 2 [Electronic resource]. Available at: https://ibima.org/accepted-paper/\%D0\%BErganizational-and-economicmechanism-for-customs-control-after-the-release-of-goodsadministration-in-the-economic-security-system.

[4] G. I. Nemirova and A. A. Vinichenko, "The mechanism of improving the quality of public services in the field of customs in terms of digital transformation", Moscow: INSTITUTE of the Russian customs Academy, 2017, $130 \mathrm{p}$. 
[10] Electronic resource. Available at: https://www.ccn.com/samsung-sds-topower-worlds-first-exports-customs-clearance-blockchain-in-korea.

[5] A, Momchil, "The role of information technologies in the development of customs control in the Republic of Bulgaria", World Customs Journal, 2017, 11, [Electronic resource]. Available at: https://www.researchgate.net/publication/321493178_The_role_of_infor mation_technologies_in_the_development_of_customs_control_in_the Republic_of_Bulgaria.

[6] S. V. Moser, "Improvement of customs regulation: formation of the theoretical foundations of the Institute of digital customs based on the approaches of the world customs organization", Problems of Economics and legal practice, 2019, T. 15, no. 4, pp. 182-191 [Electronic resource]. Available at: https://elibrary.ru/item.asp?id=39546918

[7] Electronic resource. Available at: https://www.customs.gov.sg//media/cus/files/media-releases/2018/for-website-media-release-_networked-trade-platform.pdf.

[8] T. M. Vorotyntseva, "Quality management of classification of goods at customs control", Bulletin of the Russian customs Academy, 2017, no. 2, pp. 117-122.

[9] Singapore introduces blockchain platform [Electronic resource]. Available at: https://www.gtreview.com/news/asia/singapore-chamberof-commerce-brings-trade-documents-on to-blockchain.

[11] P. Rourke, "Influence of digital technologies in trade on economic development", Trade policy, 2016 (2018), no. 4/8, pp. 132-137 [Electronic resource]. Available at: https://cyberleninka.ru/article/n/ influence-of-digital-technologies-in-trade-on-economicdevelopment/viewer.

[12] G. I. Nemirova and A. A. Ermakova, "State and prospects of development of information technologies in the system of customs control", Customs matter, 2018, no. 1, pp. 7-12.

[13] T. M. Vorotyntseva and A. S. Tultseva, "Traceability of goods as a mechanism of regulation of international trade", Marketing and logistics, 2018, no. 5 (19), pp. 22-31.

[14] H. Doesthe Meijers, "Internet generate economic growth, international trade, or both?", International Economics and Economic Policy, 2014, pp.137-163.

[15] T. M. Vorotyntseva, "Problematic issues of technical regulation in the EEU", Marketing and logistics, 2017, no. 4 (12), pp. 16-26. 